\title{
SAT, a New Approach in Understanding and Treatment of Subclinical Endometritis in Dairy Cows
}

\author{
Samia Mohamed Abd El-Rheem1* ${ }^{*}$, Rezk Said Ghallab², Suzan El-Sharkawy ${ }^{3}$ \\ ${ }^{1}$ Theriogenology Department, Faculty of Veterinary Medicine, Alexandria University, Alexandria, Egypt \\ ${ }^{2}$ Theriogenology Department, Faculty of Veterinary Medicine, Matrouh University, Matrouh, Egypt \\ ${ }^{3}$ Gynecology and Obstetrics Department, Faculty of Medicine, Alexandria University, Alexandria, Egypt \\ Email: *ssamir@alexu.edu.eg
}

How to cite this paper: El-Rheem, S.M.A., Ghallab, R.S. and El-Sharkawy, S. (2019) SAT, a New Approach in Understanding and Treatment of Subclinical Endometritis in Dairy Cows. Open Journal of Veterinary Medicine, 9, 109-119.

https://doi.org/10.4236/ojvm.2019.98010

Received: July 5, 2019

Accepted: August 26, 2019

Published: August 29, 2019

Copyright $\odot 2019$ by author(s) and Scientific Research Publishing Inc. This work is licensed under the Creative Commons Attribution International License (CC BY 4.0).

http://creativecommons.org/licenses/by/4.0/

\begin{abstract}
The aim of this work was to compare the use of local intrauterine moist heat infusion to intrauterine antibiotics infusion, for treatment of subclinical endometritis which affects reproduction and milk production. 42 repeat breeder cows were divided into 4 groups, group 1 was the untreated control $(=10$ cows). Group 2 (=10 cows) was treated by $50 \mathrm{ml}$ of Oxytetracycline $5 \%$ intrauterine for three successive weeks. Group 3 (=10 cows) intrauterine infusion with $30 \mathrm{ml}$ saline adding to them $10 \mathrm{ml}$ Gentamycin $10 \%$ and $10 \mathrm{ml}$ penicillin and streptomycin for three successive weeks. Group 4 (=12 cows) intrauterine infusion with $50 \mathrm{ml}$ sterile boiling water $\left(\approx 100^{\circ} \mathrm{C}\right)$ was applied directly to the uterus for only one time. Leukogram was done before and after treatment, it showed leukocytosis and neutrophilia in all the study groups. After treatment for 36 hours and one week, there were no significant changes in the leukogram results of groups 1, 2 and 3. While in Group 4 showed decreasing in numbers of leukocytes $(11.92 \pm 0.75)$ and neutrophils $(0.87 \pm 0.16)$ to its normal limits after 36 hours and one-week post-treatment. Our new method gave the highest cumulative pregnancy rate $83.3 \%$ while other groups using antibiotics or antibiotics with saline gave lower pregnancy rate $40 \%$ and $50 \%$ respectively $(\mathrm{P}>0.001)$. We named this new treatment method "Samia-treat; SAT". SAT is a whole new and effective treatment for cases of repeat breeder which are caused by SCE in dairy cows; it caused increase in reproductive performance and cumulative pregnancy rate without over use of antibiotics.
\end{abstract}

\section{Keywords}

Subclinical Endometritis, Repeat Breeder, Dairy Cows, Fertility 


\section{Introduction}

According to United Nations estimates, the world population is set to rise from close to 7 billion since 2010 to about 9.5 billion by 2050 [1]. An increase of about $30 \%$ will require increased food production of a similar amount. To catch up to the increasing demands of the $21^{\text {st }}$ century, individual cows should produce milk and beef more efficiently [2]. The new era of genetics progress, dairy and beef industry management throughout the entire world is fighting to meet the growing demand for products derived from cattle. Unfortunately, cow reproductive efficiency is actually decreasing worldwide. This reproductive decline needs to be reversed by collaborative efforts of breeders, veterinary doctors, and researchers [3]. Around $80 \%-100 \%$ of cattle will have bacterial contamination in the uterine lumen in the first 2 weeks postpartum [4]. This contamination is normal and unavoidable, fortunately, within a similar time span, the endometrium will slough and then regenerate. $80 \%$ of the animals usually deal with this bacterial contamination successfully; but around $20 \%$ of cows will be unable to resolve the contamination (due to deficient nutrition, metabolic disorders, body condition score loss and a pronounced negative energy balance triggering reduced immune function) and eventually will have metritis within 21 days postpartum [5]. Clinical cases of endometritis are recognized by purulent or mucopurulent vaginal discharge [6] [7]. Cows which are lucky enough to receive the prober treatment for clinical (endo) metritis will have conception rates approximately $20 \%$ lower than the unaffected animals and $3 \%$ of those animals will remain infertile and will be culled at the end [4]. Subclinical endometritis (SCE) is the least severe form of endometritis with a proportion of polymorphonuclear (PMN) cells found in the superficial endometrium which is associated with decrease reproductive performance, delay return to estrus or repeat breeder [8] [9] and may negatively affect milk production [10] with absence of abnormal discharge and systemic signs [11]. The prevalence of SCE in postpartum dairy cows has varied between $7 \%$ and $53 \%$. Such disparity may be due to differences in 1) postpartum period in which the sample was collected, 2) PMN\% threshold established for diagnosis, and 3) the method used to take the sample.

SCE cannot ever be detected by clinical inspection of the affected animals, complementary tests are essential for its diagnosis, being: histopathology, ultrasonography and endometrial cytology. Several studies showed that bacterial population isolated from the uterus of cows diagnosed with SCE did not differ from those of healthy cows [12]. In caws, the golden standard method to diagnose endometrial diseases is histo-pathological biopsy (showing inflammatory cells in the uterine endometrium, with disruption of the epithelial layer), but it is rarely used as it is time-consuming, costly and may be detrimental for further fertility [13]. Meanwhile, ultrasound is an easy and fast method to diagnose SCE (fluid in the uterine cavity between 20 to 47 days postpartum and endometrial thickness measurements), but alone it is considered to be not precise enough to assess a final diagnosis [14]. Endometrial cytology is the most commonly used 
method for the diagnosis of SCE in cattle in both field and research [15]. Cytobrush and low volume lavage are the most used techniques to harvest endometrial surface scrapings, with measurements of the percentages of PMNs in cytology slides are considered to be the hallmark for SCE diagnosis [16].

The inflammatory process associated with SCE that gather activated PMNs in the uterine lumen and starts immune receptors leading to secretion of inflammatory cytokines and chemokines [17]. This inflammatory environment hinders fertility by creating hostile conditions for sperms transport and storage, follicular growth, fertilization, implantation and embryonic and fetal growth [18], increasing the percent of sub-fertile animals in dairy farms. Clinical and subclinical endometritis have been linked to a decline in milk production of $0.6-1.03$ $\mathrm{kg} /$ cow/day, decrease milk fat and protein proportions, and with increased somatic cell counts in milk [19].

Studies on the treatment of SCE, the use of prostaglandin $\mathrm{F}_{2 \alpha}$ [20] [21] and or intrauterine antibiotics [22] [23] or non-steroidal anti-inflammatory drugs (Priest, 2013), showed heterogeneous results and do not allows valid recommendations for veterinary practice and were examined only in a few studies that can't compare between them as included different protocols, animals in different postpartum periods, and different diagnosis for SCE.

In this research, we used for the first time Moist heat (boiling water) for treatment of SCE which was used previously in the treatment of many diseases on sporadic human cases [24]. Boiling water kills or inactivates viruses, bacteria, protozoa and other pathogens (e.g. denature proteins) [25].

The aim of this work was to compare the use of local intrauterine moist heat infusion to intrauterine antibiotics infusion, for treatment of SCE. We hypothesized that treatment with moist heat would reduce the prevalence of SCE in cows and improve their reproductive performance. Therefore, our objectives were to study the effects of moist heat on uterine health and the cumulative pregnancy rate.

\section{Materials and Methods}

All experiments described in the present study were carried out with permission of the Ethical Committee of the Faculty of Veterinary Medicine, Alexandria University, Egypt, October 2018. The experiments were performed in the farm of Faculty of Agriculture, Alexandria University, Egypt in the period from October 2018 and April 2019.

\section{Animals, Feeding and Reproductive Management}

53 repeat breeder lactating Holstein cows (multiparous) with good body condition (score 3.5 - 4.0) according to the five-scale point system outlined by [26] were obtained based on their calving dates using on-farm computer records. Feeding was based on the TMR (total mixed ration) system which consisted of a mixture of concentrate containing high quality additives such as vitamins, min- 
erals, anti-mycotoxins, anti-acids, and a mixture of high quality alfalfa hay and corn silage in the same meal. The cows had no apparent signs of endometritis, normal ovarian cycles and artificial insemination (AI) with frozen semen were applied before but was failed and they came in estrus again (from four to nine regular times from the last parturition).

\section{Evaluation of the Reproductive System}

\subsection{Rectal Palpation}

We did rectal palpation before treatment as described by López-Gatius, and Camóón-Urgel [27] to exclude ovarian cysts and signs of uterine inflammation (abnormal discharge and/or uterine enlargement).

\subsection{Ultrasound}

Using a Sonoscape M12V Ultrasound B-mode (Heyi Medical Instrument Co., Ltd., Shanghai, China) with a dual-frequency 5.0/7.5 MHz. Trans-rectal transducer was done for exclusion of pregnancy and checking signs of SCE. Cows had small amount of intrauterine fluid and/or thickened uterine wall were suspected to have SCE [28] and were farther evaluated by cytology.

\section{Investigation}

\subsection{Cytological Tests}

For more conformation, we used cytological test by using intrauterine brush adapted for uterus of cows (Minitube Group Co., Ltd, Verona, USA). Under rectal guidance and by passing the instrument through the cervix (as an artificial insemination), the brush was inserted into the uterine lumen and with gentle rotation against the uterine wall, endometrial cytology samples were obtained as described by [29]. Cytological slides were prepared by rolling the brush onto clean glass slides and were sent to the laboratory within an hour. Based on the uterine cytology, 42 cows had PMN count > 5\% was considered SCE cases. The cow selection process was based on the literature of [29].

\subsection{Leukogram}

Peripheral blood samples $(2 \mathrm{ml})$ were collected from the tail vein in (EDTA/K3) tubes for counting the total leukocytes and differential leukocytic count before treatment with automated cell counter (Two blood samples were collected and counted from each animal and take the mean).

\section{Treatment}

The repeat breeder cows divided into 4 groups, group 1 was untreated the control (=10 cows). Group 2 (=10 cows) was treated by $50 \mathrm{ml}$ of Oxytetracycline $5 \%$ (Pharma Swede Co., Egypt) intrauterine and repeated the treatment for three successive weeks. Group 3 (=10 cow) the uterus was infused with $30 \mathrm{ml}$ saline 
adding to them $10 \mathrm{ml}$ Gentamycin 10\% (Pharma swede Co., Egypt) and $10 \mathrm{ml}$ penicillin and streptomycin(Procaine Penicillin $200 \mathrm{mg}$ Dihydrostreptomycin Sulphate $250 \mathrm{mg}$ ) (Norbrook Co. Newry, United Kingdom) repeated the treatment for three successive weeks. Group 4 (=12 cows) intrauterine infusion with $50 \mathrm{ml}$ of boiling sterile water $\left(\approx 100^{\circ} \mathrm{C}\right)$ was applied directly into the uterus by using stainless steel catheter (Taba Medical Pharma Co. Cairo, Egypt) and 100 $\mathrm{ml}$ syringe for only one time.

\section{Evaluation of the Treatment}

\subsection{Rectal Palpation}

For each animal in the 4 groups, rectal palpation was done on day 2 and day 3 after treatment to assess local uterine signs.

\subsection{Leukogram}

As previously described, differential leukocytic count was made 36 hours and one week after treatment for all the study groups (Two blood samples were collected and counted from each animal and take the mean).

\subsection{AI and Pregnancy Diagnosis}

AI using frozen semen was done for three successive cycles to all the study groups from the first estrus exhibited after treatment. Following each AI the animals which did not show estrus signs were examined by transrectal ultrasound at $30 \pm 3$ days post-AI for pregnancy diagnosis. Reconfirmation of pregnancy was made approximately 30 days. Cows which showed estrus and by trans-rectal ultrasound had mature follicle with no corpus leutum were reinseminated.

\section{Statistical Analysis}

All analyses were performed with SPSS for Windows (version 22, IBM Corp., Armonk, NY, USA). Total leukocytes and neutrophils counts were expressed as the mean \pm standard error of mean. Because of small group size and lack of normality and/or homogeneity of variances, differences among groups were assessed with the non-parametric Kruskal-Wallis test with Dunn's post hoc test for multiple comparisons. We used Fisher's exact test for categorical data (conception rates). A probability value of 0.05 or less was considered statistically significant.

\section{Results}

53 repeat breeder lactating Holstein cows were recruited for this study, 11 cows were excluded (20.7\%). 3 cows (5.6\%) were excluded due to the presence of ovarian cysts during rectal palpation, one cow (1.9\%) due to the presence of abnormal vaginal discharge and 7 cows (13.2\%) there PMN were $<5 \%$ in their cytology. 


\subsection{Rectal Palpation}

The remaining 42 animals were randomly divided into 4 study groups. Rectal palpation was done for all animal groups, with non-specific findings in the first three groups (control and local antibiotic groups). On the other hand, all cows of group 4 (moist heat group; 12 animals) had got turgid, erected and coiled uteri upon rectal palpation done on day 2 and 3 post-treatment (100\%).

\subsection{Leukogram}

Regarding blood analysis done before starting different treatment strategies, it showed leukocytosis and neutrophilia in all the study groups. There were no significant changes in the leukogram results of groups 1, 2, 3 after 36 hours and after one week of treatment application, with persistent leukocytosis and neutrophilia in these groups. While in Group 4, leukogram done after 36 hours post-treatment showed marked decrease in numbers of leukocytes (11.92 \pm 0.75$)$ and numbers of neutrophils $(0.87 \pm 0.16)$ almost to its normal limits. This "back to normality" sign persisted in the next leukogram tests done after one-week post-treatment, as shown in Table 1 and Table 2.

\section{The Cumulative Pregnancy Rate}

The cumulative pregnancy rate for control group (group 1) after the first three inseminations was $0 \%$. For the remaining 3 groups, first insemination conception rate was $(20 \%)$ in groups 2 and group 3 which was lower $(\mathrm{P}<0.05)$ than

Table 1 . Total leukocytic count $\left(10^{3} / \mu \mathrm{l}\right)$ in different study groups.

\begin{tabular}{ccccc}
\hline \multirow{2}{*}{ Group } & \multicolumn{3}{c}{ Time } & Normal limit \\
\cline { 2 - 4 } & Before treatment & After 36 h & After 1 week & \\
\hline 1 & $40.67 \pm 4.11^{\mathrm{a}}$ & $40.48 \pm 4.06^{\mathrm{a}}$ & $39.53 \pm 4.10^{\mathrm{a}}$ & \\
2 & $40.99 \pm 3.70^{\mathrm{a}}$ & $40.78 \pm 2.60^{\mathrm{a}}$ & $39.78 \pm 3.55^{\mathrm{a}}$ & \\
3 & $40.88 \pm 4.14^{\mathrm{a}}$ & $39.95 \pm 3.34^{\mathrm{a}}$ & $38.38 \pm 3.44^{\mathrm{a}}$ & \\
[George et al., 2010]
\end{tabular}

Values are means and standard error of means. Means in a column without a common superscript letter differ significantly $(\mathrm{P}<0.05)$.

Table 2. Segmented neutrophil count $\left(10^{3} / \mu \mathrm{l}\right)$ in different study groups.

\begin{tabular}{ccccc}
\hline \multirow{2}{*}{ Group } & \multicolumn{3}{c}{ Time } & Normal limit \\
\cline { 2 - 4 } & Before treatment & After 36 h & After 1 week & \\
\hline 1 & $6.09 \pm 0.29^{\mathrm{a}}$ & $5.59 \pm 0.21^{\mathrm{a}}$ & $6.09 \pm 0.29^{\mathrm{a}}$ & \\
2 & $6.07 \pm 0.38^{\mathrm{a}}$ & $5.77 \pm 0.30^{\mathrm{a}}$ & $6.07 \pm 0.38^{\mathrm{a}}$ & $1.8-6.3$ \\
3 & $5.81 \pm 0.36^{\mathrm{a}}$ & $5.51 \pm 0.28^{\mathrm{a}}$ & $5.81 \pm 0.36^{\mathrm{a}}$ & [George et al., 2010] \\
4 & $5.91 \pm 0.36^{\mathrm{a}}$ & $0.87 \pm 0.16^{\mathrm{b}}$ & $1.21 \pm 0.24^{\mathrm{b}}$ & \\
\hline
\end{tabular}

Values are means and standard error of means. Means in a column without a common superscript letter differ significantly $(\mathrm{P}<0.05)$. 
group $4(33.3 \%)$. The cumulative pregnancy rate after the $1^{\text {st }}$ two inseminations was $30 \%$ in groups $2,50 \%$ in group 3 which was lower $(\mathrm{P}<0.01)$ than group 4 (66.7\%). While the cumulative pregnancy rate after the $1^{\text {st }}$ three inseminations was $40 \%$ in groups $2,50 \%$ in group 3 and $83.3 \%$ in group 4 , which was higher (P $<0.001)$ than other groups as shown in Table 3.

\section{Discussion}

In many cases of SCE, there is negative bacterial culture and/or no uterine content [30]. This may explain the failure that is usually encountered with antibiotic treatments. In human, there is no such a similar condition of SCE, which may be due to the monthly shedding of the women endometrium [31], and its regular regeneration that prevents the accumulation of bacteria and other pathogens that will trigger cells like PMN. However, in cattle the endometrium shedding occurs only after parturition and then it regenerates itself [32]. After that, no menstruation happens, only the endometrium just increases or decreases in thickness each estrous cycle in response to ovarian steroid hormones [33].

This study was designed to evaluate the effect of a completely new treatment idea on cases of repeat breeder diagnosed as SCE. We used moist heat (boiling water) to induce endometrial burn and necrosis that will be sloughed and induce regeneration with a new healthy endometrium which will permit successful implantation and ongoing pregnancy.

There were no limitations in this study, rectal palpation of group 4 (group of moist heat) on day 2 and 3 post-treatment showed that all animals had turgid, erected and coiled uterus, our explanation that there was uterine muscular contraction for sloughing of necrotic tissues [34] and regeneration of the endometrium by epithelial progenitor and mesenchymal stem cells which spontiuosly regenerate uterus after parturition [35] [36]. The cumulative pregnancy rate with group 4 (group of moist heat) reached up to $83.3 \%$ after 3 successive AI cycles, which was higher in favor of the new treatment group. Also, it is noteworthy that the new treatment group showed normalization in the leukogram done after 36 hours post-treatment and maintained after one week as well. These findings may indicate that the inflammatory process occurring in SCE (which caused

Table 3. Cumulative pregnancy rates in different study groups.

\begin{tabular}{|c|c|c|c|c|c|c|c|}
\hline \multirow{2}{*}{ Group } & \multirow{2}{*}{ No. } & \multicolumn{2}{|c|}{$\begin{array}{l}1^{\text {st }} \text { insemination } \\
\text { conception rate }\end{array}$} & \multicolumn{2}{|c|}{$\begin{array}{l}1^{\text {st }} \text { two inseminations } \\
\text { conception rate }\end{array}$} & \multicolumn{2}{|c|}{$\begin{array}{c}1^{\text {st }} \text { three inseminations } \\
\text { conception rate }\end{array}$} \\
\hline & & No. & $\%$ & No. & $\%$ & No. & $\%$ \\
\hline 1 & 10 & 0 & 0 & 0 & 0 & 0 & 0 \\
\hline 2 & 10 & 2 & 20 & 3 & 30 & 4 & 40 \\
\hline 3 & 10 & 2 & 20 & 5 & 50 & 5 & 50 \\
\hline 4 & 12 & 4 & 33.3 & 8 & 66.7 & 10 & 83.3 \\
\hline$P$ value* & & $>0.05$ & & $<0.01$ & & $<0.001$ & \\
\hline
\end{tabular}

${ }^{\star}$ Based on Fisher's exact test. 
increased leukocytes in blood samples before starting treatment [37]), was treated in group 4 (moist heat group) while no changes affected the leukogram of the control or antibiotic groups.

This is, to the best of our knowledge, the first study that evaluated a new treatment strategy in cases of SCE, in which we did not consider the disease as a local infection to give antibiotic, but we induced a correctable injury to regenerate a whole new endometrium mimicking the human menstruation idea.

Conflicting result was obtained from a few studies than included animals in dissimilar situations such as different postpartum periods and different synchronization protocols for estrus and/or ovulation. That made it very difficult to be compared to each other to get a final conclusion on the effect of various treatment protocols.

We named this new treatment method "Samia-treat; SAT" after the name of first one to describe it, farther studies on a wider number of animals are needed to confirm our result, and get a better understanding of the mechanism which truly occurs in SAT.

\section{Conclusion}

SAT is a whole new and effective treatment for cases of repeat breeder caused by SCE in cows; it caused an increase in reproductive performance and cumulative pregnancy rate while it almost costs nothing.

\section{Conflicts of Interest}

The authors declare that they have no conflict of interest.

\section{References}

[1] Conway, G. (2012) One Billion Hungry: Can We Feed the World? Cornell University Press, Ithaca, 456.

[2] Lucy, M. (2001) Reproductive Loss in High-Producing Dairy Cattle: Where Will It End? Journal of Dairy Science, 84, 1277-1293. https://doi.org/10.3168/jds.S0022-0302(01)70158-0

[3] Walsh, S., Williams, E. and Evans, A. (2011) A Review of the Causes of Poor Fertility in High Milk Producing Dairy Cows. Animal Reproduction Science, 123, 127-138. https://doi.org/10.1016/j.anireprosci.2010.12.001

[4] Sheldon, I.M., Cronin, J., Goetze, L., Donofrio, G. and Schuberth, H.J. (2009) Defining Postpartum Uterine Disease and the Mechanisms of Infection and Immunity in the Female Reproductive Tract in Cattle. Biology of Reproduction, 81, 1025-1032. https://doi.org/10.1095/biolreprod.109.077370

[5] Herath, S., Dobson, H., Bryant, C. and Sheldon, I. (2006) Use of the Cow as a Large Animal Model of Uterine Infection and Immunity. Journal of Reproductive Immunology, 69, 13-22. https://doi.org/10.1016/j.jri.2005.09.007

[6] McDougall, S., Macaulay, R. and Compton, C. (2007) Association between Endometritis Diagnosis Using a Novel Intravaginal Device and Reproductive Performance in Dairy Cattle. Animal Reproduction Science, 99, 9-23. https://doi.org/10.1016/j.anireprosci.2006.03.017 
[7] Pleticha, S., Drillich, M. and Heuwieser, W. (2009) Evaluation of the Metricheck Device and the Gloved Hand for the Diagnosis of Clinical Endometritis in Dairy Cows. Journal of Dairy Science, 92, 5429-5435. https://doi.org/10.3168/jds.2009-2117

[8] Janowski, T., Barański, W., Łukasik, K., Skarżyński, D., Rudowska, M. and Zduńczyk, S. (2013) Prevalence of Subclinical Endometritis in Repeat Breeding Cows and mRNA Expression of Tumor Necrosis Factor $\alpha$ and Inducible Nitric Oxide Synthase in the Endometrium of Repeat Breeding Cows with and without Subclinical Endometritis. Polish Journal of Veterinary Sciences, 16, 693-699.

https://doi.org/10.2478/pjvs-2013-0098

[9] Pothmann, H., Prunner, I., Wagener, K., Jaureguiberry, M., La Sota, R.L., Erber, R., Aurich, C., Ehling-Schulz, M. and Drillich, M. (2015) The Prevalence of Subclinical Endometritis and Intrauterine Infections in Repeat Breeder Cows. Theriogenology, 8, 1249-1253. https://doi.org/10.1016/j.theriogenology.2015.01.013

[10] Green, M.P., Ledgard, A.M., Berg, M.C., Peterson, A.J. and Back, P.J. (2009) Prevalence and Identification of Systemic Markers of Sub-Clinical Endometritis in Postpartum Dairy Cows. Proceedings of the New Zealand Society of Animal Production, 6, 37-42.

[11] Sheldon, I.M., Price, S.B., Cronin, J., Gilbert, R.O. and Gadsby, J.E. (2009) Mechanisms of Infertility Associated with Clinical and Subclinical Endometritis in High Producing Dairy Cattle. Reproduction in Domestic Animals, 44, 1-9. https://doi.org/10.1111/j.1439-0531.2009.01465.x

[12] Mariño, B., Quintela, L.A., Becerra, J.J., Barrio, L., Mociños, J.E., Guillin, J.L., et al. (2017) Agreement between Postmortem Endometrial Cytology, Biopsy and Bacteriology in Culled Dairy Cows. Animal Reproduction, 14, 1024-1033. https://doi.org/10.21451/1984-3143-AR826

[13] Sheldon, I.M. and Dobson, H. (2004) Postpartum Uterine Health in Cattle. Animal Reproduction Science, 82-83, 295-306. https://doi.org/10.1016/j.anireprosci.2004.04.006

[14] Barlund, C.S., Carruthers, T.D., Waldner, C.L. and Palmer, C.W. (2008) A Comparison of Diagnostic Techniques for Postpartum Endometritis in Dairy Cattle. Theriogenology, 69, 714-723. https://doi.org/10.1016/j.theriogenology.2007.12.005

[15] De Boer, M.W., LeBlanc, S.J., Dubuc, J., Meier, S., Heuwieser, W. and Arlt, S. (2014) Invited Review: Systematic Review of Diagnostic Tests for Reproductive-Tract Infection and Inflammation in Dairy Cows. Journal of Dairy Science, 97, 3983-3999. https://doi.org/10.3168/jds.2013-7450

[16] Kasimanickam, R., Cornwell, J. and Nebel, R. (2006) Effect of Presence of Clinical and Subclinical Endometritis at the Initiation of Presynch-Ovsynch Program on the First Service Pregnancy in Dairy Cows. Animal Reproduction Science, 95, 214-223. https://doi.org/10.1016/j.anireprosci.2005.10.007

[17] Hailemariam, D., Ibrahim, S., Hoelker, M., Drillich, M., Heuwieser, W. and Looft, C. (2014) MicroRNA-Regulated Molecular Mechanism Underlying Bovine Subclinical Endometritis. Reproduction, Fertility and Development, 26, 898-913. https://doi.org/10.1071/RD13027

[18] Gilbert, R.O. (2011) The Effects of Endometritis on the Establishment of Pregnancy in Cattle. Reproduction, Fertility and Development, 24, 252-257. https://doi.org/10.1071/RD11915

[19] McDougall, S., Hussein, H., Aberdein, D., Buckle, K., Roche, J., Burke, C., et al. (2011) Relationships between Cytology, Bacteriology and Vaginal Discharge Scores 
and Reproductive Performance in Dairy Cattle. Theriogenology, 76, 229-240. https://doi.org/10.1016/j.theriogenology.2010.12.024

[20] Galvão, K.N., Frajblat, M., Brittin, S.B., Butler, E.R., Guard, C.L. and Gilbert, R.O. (2009) Effect of Prostaglandin $\mathrm{F}_{2 \alpha}$ on Subclinical Endometritis and Fertility in Dairy Cows. Journal of Dairy Science, 92, 4906-4913. https://doi.org/10.3168/jds.2008-1984

[21] Lima, F.S., Bisinotto, R.S., Ribeiro, E.S., Greco, L.F., Ayres, H., Favoreto, M.G., et al. (2013) Effects of 1 or 2 Treatments with Prostaglandin $F_{2 \alpha}$ on Subclinical Endometritis and Fertility in Lactating Dairy Cows Inseminated by Timed Artificial Insemination. Journal of Dairy Science, 96, 6480-6488. https://doi.org/10.3168/jds.2013-6850

[22] Galvão, K.N., Greci, L.F., Vilela, J.M., Sá Filho, M.F. and Santos, J.E.P. (2009) Effect of Intrauterine Infusion of Ceftiofur on Uterine Health and Fertility in Dairy Cows. Journal of Dairy Science, 92, 1532-1542. https://doi.org/10.3168/jds.2008-1615

[23] Denis-Robichaud, J. and Dubuc, J. (2015) Randomized Clinical Trial of Intrauterine Cephapirin Infusion in Dairy Cows for the Treatment of Purulent Vaginal Discharge and Cytological Endometritis. Journal of Dairy Science, 98, 6856-6864. https://doi.org/10.3168/jds.2014-9129

[24] Abd-El-Rheem, M.S.A. (1997) The Use of Moist Heat as Immuno Stimulant in Defentive Treatment of Cutaneous Cancer and Other Affections. Alexandria Journal of Veterinary Science (Egypt), 13, 533-538.

[25] WHO (2011) Water Sanitation Health Guidelines.

[26] Wildman, G.M., Kotwiga, J., Slanger, W. and Johnson, K. (1982) Effects of Suckling on Pituitary Responsiveness to GnRH Hormones throughout the Early Postpartum of Beef Cows. Journal of Animal Science, 54, 594-603. https://doi.org/10.2527/jas1982.543594x

[27] López-Gatius, F. and Camóón-Urgel, J. (1991) Confirmation of Estrus Rates by Palpation per Rectum of Genital Organs in Normal Repeat Dairy Cows. Journal of Veterinary Medicine Series A, 38, 553-556. https://doi.org/10.1111/j.1439-0442.1991.tb01047.x

[28] Priest, N. (2013) The Effect of a Non-Steroidal Anti-Inflammatory Drug on Subclinical Endometritis in Dairy Cows and the Identification of At-Risk Cows. MSc Thesis, Lincoln University, Christchurch.

[29] Kasimanickam, R., Duffield, T.F., Foster, R.A., Gartley, C.J., Leslie, K.E., Walton, J.S., et al. (2004) Endometrial Cytology and Ultrasonography for the Detection of Subclinical Endometritis in Postpartum Dairy Cows. Theriogenology, 62, 9-23. https://doi.org/10.1016/j.theriogenology.2003.03.001

[30] Arias, L.A.Q., Fernández, M.V., González, J.J.B., López, M.B., Herradón, P.G. and Martínez, A.I.P. (2018) Subclinical Endometritis in Dairy Cattle. In: New Insights into Theriogenology, IntechOpen, London, 80-81. https://doi.org/10.5772/intechopen.80229

[31] Profet, M. (1993) Menstruation as a Defense against Pathogens Transported by Sperm. The Quarterly Review of Biology, 68, 335-386. https://doi.org/10.1086/418170

[32] Tian, W. and Noakes, D.F. (1991) A Radiographic Method for Measuring the Effect of Exogenous Hormone Therapy on Uterine Involution in Ewes. Veterinary Record, 129, 463-466. https://doi.org/10.1136/vr.129.21.463

[33] Sugiura, T., Akiyoshi, S., Inoue, F., Yanagawa, Y., Moriyoshi, M., Tajima, M. and Katagiri, S. (2018) Relationship between Bovine Endometrial Thickness and Plasma 
Progesterone and Estradiol Concentrations in Natural and Induced Estrus. Journal of Reproduction and Development, 64, 135-143.

https://doi.org/10.1262/jrd.2017-139

[34] Gier, H.T. and Marion, G.B. (1968) Uterus of the Cow after Parturition: Involutional Changes. American Journal of Veterinary Research, 29, 83-96.

[35] Patterson, A.L. (2013) Mechanisms of Endometrial Regeneration. Washington State University, Pullman.

[36] Cousins, F.L. and Gargett, C.E. (2018) Endometrial Stem/Progenitor Cells and Their Role in the Pathogenesis of Endometriosis. Best Practice \& Research Clinical Obstetrics \& Gynaecology, 50, 27-38. https://doi.org/10.1016/j.bpobgyn.2018.01.011

[37] Roland, L., Drillich, M. and Iwersen, M. (2014) Hematology as a Diagnostic Tool in Bovine Medicine. Journal of Veterinary Diagnostic Investigation, 26, 592-598.

https://doi.org/10.1177/1040638714546490 